\title{
Feasibility of Cladding Ti to Carbon Steel by Diffusion Bonding Followed by Hot-rolling
}

\author{
S.R. Ke, X.H. Xu and Z.D.Xiang* \\ The State Key Laboratory of Refractories and Metallurgy, School of Materials and Metallurgy, \\ Wuhan University of Science and Technology, Wuhan, P R China, 430081. \\ * corresponding author, email: zhidongxiang@hotmail.com
}

\begin{abstract}
Keywords: Ti-clad steel; Diffusion bonding; Hot-rolling; Carbon steel; Heat treatment.
Abstract. Ti was diffusion-bonded to a grade of carbon steel containing about $0.13 \mathrm{wt} \% \mathrm{C}$. The diffusion- bonded specimen was then hot-rolled to a final reduction in thickness of about $71 \%$. There were no delaminations during hot-rolling. The cross sectional microstructures of specimens before and after hot-rolling were characterised using scanning electron microscopy, energy dispersive spectroscopy and optical microscopy. It was proved that it is technically feasible to produce Ti-clad carbon steel plates using a process of diffusion bonding followed by hot-rolling. It was also demonstrated that normal heat treatment procedures involving quenching and tempering can be applied to Ti-clad carbon steels after hot-rolling. The bond strength of the claddings would be determined by the intermetallic compound phases formed at the interface between $\mathrm{Ti}$ and carbon steel, which could be optimised by adjusting the conditions of diffusion bonding and hot rolling processes.
\end{abstract}

\section{Introduction}

Titanium, due to its corrosion resistance, is an ideal material for applications in corrosive media or environments or in areas where contamination by corrosion is of a primary concern. But, it is also expensive, which restricts its use in areas where cost is an important consideration. On the other hand, carbon steels are low cost materials with mechanical properties modifiable by heat treatments. Thus, cladding carbon steels with a thin layer of Ti may offer a cost effective material with a combination of corrosion resistance and mechanical strength properties suitable for structural applications in corrosive environments, particularly in marine environments. Ti-clad steel plates are produced at present mostly by explosive bonding process, which is normally followed by rolling to flatten the plates and to produce the required thickness [1-3]. However, the explosive bonding process is difficult to control and not environmentally friendly. Edge welding in vacuum followed by hot rolling is another possible process for producing Ti-clad steel plates, but welding Ti to steel can be difficult due to the formation of brittle intermetallic compound phases [4-5] and as a consequence the welded edges may not be strong enough to hold the two dissimilar metals together when the welded plates are fed into rolling machine, causing splitting during hot rolling. Thus, alternative processes that can avoid these difficulties need to be developed for producing Ti-clad steel plates.

A number of studies have been reported on diffusion bonding of Ti or Ti-alloys to steels [6-9] and the bond strength between $\mathrm{Ti}$ and steel is found to depend on the microstructure formed in the interfacial region, which are affected by processing conditions, steel composition and interlayer metal used in the process. However, there have been no reports on the feasibility of hot-rolling such diffusion bonded Ti-clad steels to plates of different thicknesses. This study is undertaken to investigate this aspect with an aim to identify a new process for producing Ti-clad steels.

\section{Experimental Methods}

Materials. Commercially pure Ti of $2 \mathrm{~mm}$ thickness and carbon steel Q235 of $3 \mathrm{~mm}$ thickness with approximately $0.13 \mathrm{wt} \% \mathrm{C}$ were used in the study. Both metals were cut into a dimension of $60 \mathrm{~mm} \times$ $16 \mathrm{~mm}$. To facilitate diffusion bonding, the steel was electroplated with a Ni layer of $1.5 \mu \mathrm{m}$ thickness 
using the conventional Watts process. Both Ti and carbon steel specimens were thoroughly degreased prior to the diffusion bonding process.

Diffusion Bonding and Hot Rolling. The two metals to be diffusion-bonded were clamped between two creep resistant steel plates using bolts and nuts, which were tightened as hard as possible using a spanner by hand. The whole assembly was inserted into a tube furnace, which was then evacuated and flashed with high purity Ar, and this cycle was repeated three times. The furnace was then heated to $1000{ }^{\circ} \mathrm{C}$ under a high purity Ar atmosphere. After dwelling at this temperature for a required length of time, it was cooled to room temperature by switching off the power. The Ti-clad steel plate was heated again to $900{ }^{\circ} \mathrm{C}$ and after dwelling for 10 minutes it was taken out of the furnace and hot-rolled subsequently by immediately feeding it into a rolling machine.

Interfacial Microstructure Characterisation. The microstructure in the interfacial region of the specimens was analysed by scanning electron microscopy (SEM), energy dispersive spectroscopy (EDS) and optical microscopy (OM). The specimens were cut out of the plate in a direction vertical to the bond plane and ground and polished according to the standard metallographic procedures.

\section{Results and Discussion}

Ti-clad Carbon Steel by Diffusion Bonding. The pressure applied onto the specimen was generated by tightening the bolts and nuts of the fixture used for holding $\mathrm{Ti}$ and carbon steel plates together during the diffusion bonding process. This pressure was unquantifiable; the tightening can only ensure that the surfaces of the two metals to be bonded are in close physical contact. As no additional pressure was applied onto the specimens during diffusion bonding process, the specimens could be bonded only when temperature was higher than $900{ }^{\circ} \mathrm{C}$. This finding is slightly different from those reported previously, which showed that good bonding could form at much lower temperatures when much higher pressures were applied and maintained throughout the bonding process [6-9]. Fig. 1 shows an overall view of a specimen bonded at $1000{ }^{\circ} \mathrm{C}$ for $1 \mathrm{~h}$. The two outer Ti layers bonded well to the carbon steel in the middle (Fig. 1a). Examination of the polished cross section by optical microscopy confirmed that there were no delaminations or cracks in the interfacial region (Fig. 1b). Four layers in the interfacial region can be identified on the optical micrograph, which are marked as A, B, C, D in Fig. 1b. The layer $\mathrm{D}$, which is characterised by the absence of pearlite, is clearly a decarburised layer in carbon steel. Plot of the thickness of this layer $d_{\mathrm{C}}$ versus square root of diffusion time $t^{1 / 2}$ reveals a straight line (Fig. 1c), indicating that the growth of this layer is controlled by diffusion. Detailed microstructural analysis to be described in the following section suggests that this decarburised layer was formed as a consequence of TiC precipitation at the boundaries both between layers $\mathrm{B}$ and $\mathrm{C}$ and between layers $\mathrm{C}$ and $\mathrm{D}$ in a region where Ti had penetrated.

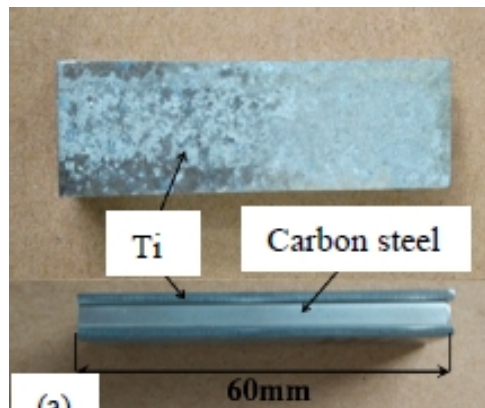

(a)
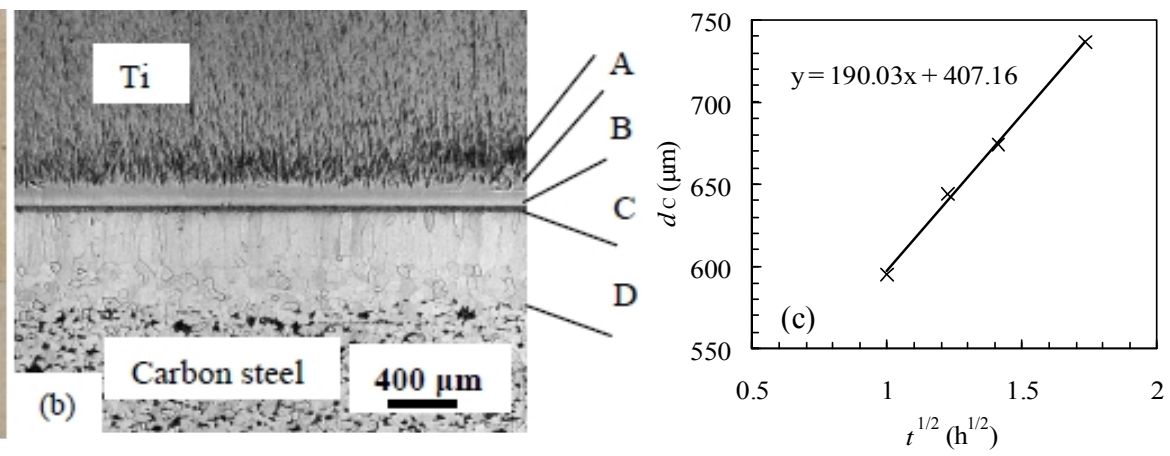

Fig. 1 Features of Ti-clad carbon steel after diffusion bonding at $1000{ }^{\circ} \mathrm{C}$ : (a) appearance of the specimen after diffusion bonding for $1 \mathrm{~h}$; (b) cross sectional optical micrograph for the specimen in (a); (c) plot of decarburised layer thickness $d_{\mathrm{c}}$ versus square root of diffusion time $t^{1 / 2}$.

Microstructure of Interface after Diffusion Bonding. Detailed SEM/EDS analyses revealed that layer A in Fig. $1 \mathrm{~b}$ has a Widmanstätten structure consisting of $\alpha$ - and $\beta$-Ti (Fig. 2b). This structure was 
formed during cooling and the precipitation of $\beta$-Ti was due to the presence of Fe, which was diffused into this layer from carbon steel (Fig. 2a). The element concentrations measured by EDS (Fig. 2a) suggest that layer $\mathrm{B}$ in Fig. $1 \mathrm{~b}$ is $\beta$-Ti. This phase was stabilised because the concentration of $\mathrm{Fe}$ diffused into Ti reached sufficiently high levels. The slim dark band in Fig. $2 \mathrm{~b}$ corresponds to layer $\mathrm{C}$ in Fig. 1b. Under an enlarged magnification, this layer had a complex structure consisting of discontinuous layers of different phases (Fig. 2c). The dark phase growing into $\beta$-Ti layer was TiC, which was precipitated when carbon diffusion reached $\mathrm{Ti}$. The brighter phase beneath $\mathrm{TiC}$ was $\mathrm{TiFe}$, the darker gray phase next to $\mathrm{TiFe}$ was $\mathrm{Ti}_{2} \mathrm{Fe}$ and the lighter gray phase in the vicinity of decarburized layer was $\mathrm{TiFe}_{2}$. TiC particles were also present in these intermetallic phases. Thus, layer $\mathrm{C}$ in Fig. $1 \mathrm{~b}$ is a mixture of carbide and intermetallic compound (IMC) phases. The total thickness of this mixture layer was about $10 \mu \mathrm{m}$. It can also be seen that $\mathrm{TiC}$ also precipitated within the grains and on the grain boundaries in the decarburized layer in a region next to layer $\mathrm{C}$. Thus, the formation of decarburized layer, i.e, layer D in Fig. 1b, was caused almost solely by the rapid precipitation of TiC phase, which took place when Ti diffused into carbon steel and when carbon reached Ti. As all the phases in layer $\mathrm{C}$ are brittle, the presence of this layer would weaken the bond strength between the two dissimilar metals. However, it was found that such diffusion bonded Ti-clad carbon steel can be hot-rolled without delaminations occurring at this brittle phase layer.
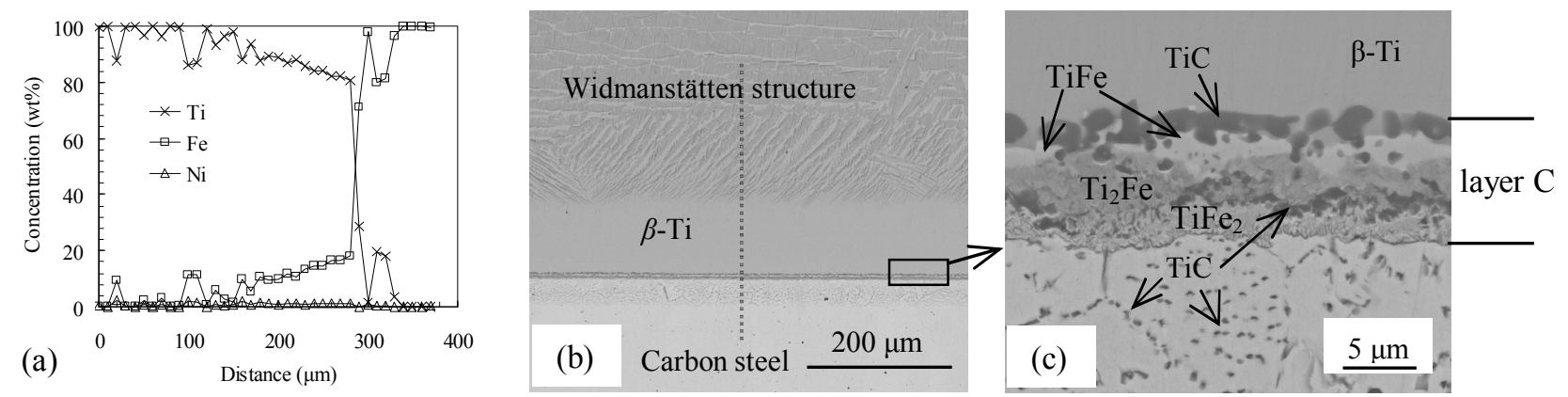

Fig. 2 Cross sectional microstructure of the Ti/carbon steel joint formed after diffusion bonding at $1000{ }^{\circ} \mathrm{C}$ for $1 \mathrm{~h}$ : (a) element concentration profiles measured by EDS along the dotted line in (b); (b) SEM image; (c) enlarged SEM image of an area marked by the oblong in (b).
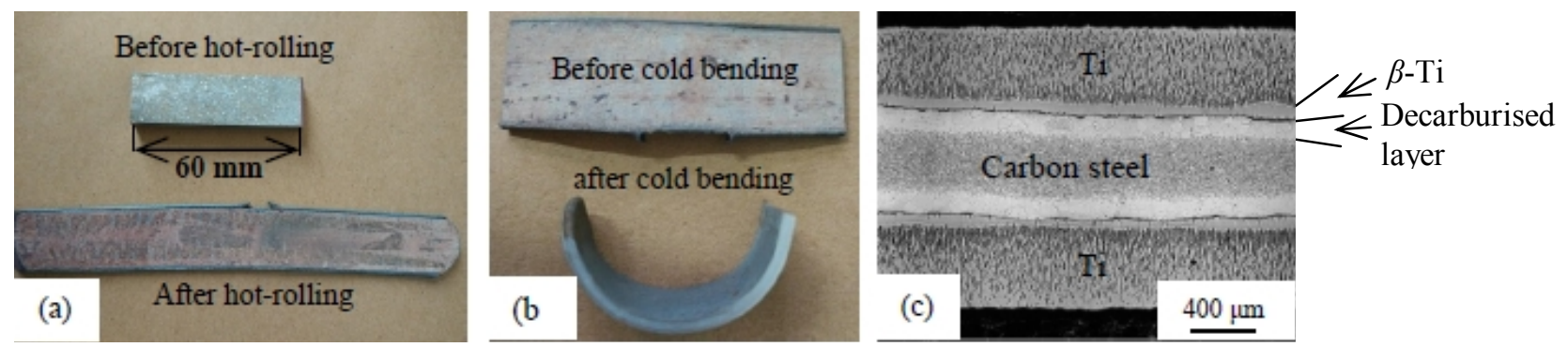

Fig.3 Overview of hot-rolled specimen: (a) specimen before and after hot-rolling; (b) specimen before and after cold-bending; (c) cross sectional optical micrograph of hot-rolled specimen.

Hot-rolling. The diffusion bonded Ti/carbon steel plates were heated again to $900{ }^{\circ} \mathrm{C}$ and after dwelling for 10 minutes, it was hot-rolled by feeding it into a rolling machine. This heating $\rightarrow$ rolling cycle was repeated after each rolling pass until the thickness of the plates was reduced from $\sim 7 \mathrm{~mm}$ to $\sim 2 \mathrm{~mm}$, i.e., a reduction of about $71 \%$. No delamination was observed during the whole hot-rolling process. This is shown in Fig. 3a, which compares the specimens before and after hot-rolling. Thus, the bond strength formed during diffusion bonding between Ti and carbon steel was strong enough to sustain the plastic deformations during hot-rolling. The hot-rolled specimen was cold-bent and, again, there was no delamination at the interfacial layers (Fig. 3b), suggesting that the bond strength after hot-rolling was sufficiently high to withstand the plastic deformation during cold-bending. Fig. 3c shows a cross-sectional optical micrograph for the specimen after hot-rolling, which shows similar 
microstructural features as those observed for the specimen after diffusion bonding and confirms that there were no delaminations at interfacial layers after hot-rolling.

Interfacial Microstructure after Hot-rolling. The interfacial microstructure of hot-rolled plate differed in a number of ways from that after diffusion bonding. First, the layer with a Widmanstätten structure in the vicinity of $\beta$-Ti layer was confined to a much narrower region (Fig. 4b). The presence of this layer was not as obvious as in the diffusion bonded specimen but recognisable, which is probably due to fact that the cooling during hot-rolling was much faster than during diffusion bonding process in which the specimen was cooled inside the furnace. Second, the $\beta$-Ti layer became much thinner after hot-rolling as compared with that before hot-rolling (Fig. 4a and b), indicating that a large amount of plastic deformation occurred in this layer during hot-rolling. This is not surprising as $\beta$-Ti has sufficiently large plasticity at high temperatures. Third, the brittle phase layer originally present in the diffusion bonded specimen, i.e., the layer $\mathrm{C}$ as shown in Fig. 2c, was not deformed but fragmented during hot-rolling, indicating that it has poor plasticity even at high temperatures. The fragments were distributed along the boundary region between $\beta$-Ti and decarburised layers (Fig. 4b). And finally, a new interface layer was formed between $\beta$-Ti and decarburised layers during hot-rolling (Fig. 4c). It was likely that it was formed during repeated heating between rolling passes. At the end of hot-rolling, the thickness of this newly formed interfacial layer was less than $300 \mathrm{~nm}$. Thus, the phase identification of this layer requires the analysis using transmission electron microscopy, which is however beyond the scope of present study. But, it is likely to be one of the intermetallic compound phases in Ti-Fe alloy system. And hence the bond strength between Ti and carbon steel will be affected by the strength of these intermetallic compound phases.
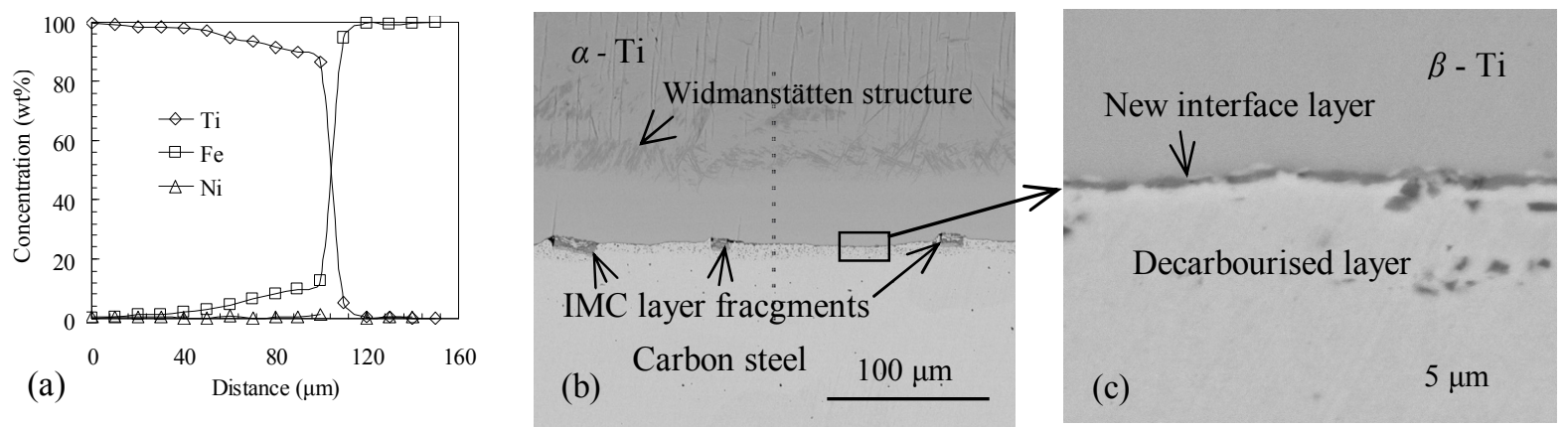

Fig. 4 Interfacial microstructure of the specimen after hot-rolling: (a) element concentration profiles at the cross section measured by EDS; (b) cross sectional SEM image; (c) enlarged SEM image for an area marked by the oblong in (b).

Heat Treatment after Hot-rolling. The strength of carbon steels can be adjusted by heat treatment, which involves quenching and tempering. To find out whether the bond strength of the Ti-clad steel after hot-rolling is strong enough to withstand the quenching operation, the hot-rolled specimen of 2 $\mathrm{mm}$ thickness was heated to $900^{\circ} \mathrm{C}$. After dwelling for 5 minutes, it was quenched in cold water and no delamination or cracking was observed, confirming that normal heat treatment procedures can be applied to the hot-rolled Ti-clad carbon steel.

After water quenching from $900{ }^{\circ} \mathrm{C}$, the carbon steel in the middle of the specimen was fully transformed to martensite (Fig. 5a). The microstructure obtained consisted of multiple phase layers. The outermost phase layer was $\alpha$-Ti, which was followed sequentially by $\beta$-Ti layer, decarburised layer and martensite. On enlarged magnification, it can be seen that there existed a region between decarburized layer and martensite where a duplex phase structure consisting of ferrite and martensite was present (Fig. 5b). The Vickers hardness profile measured across different layers showed that the highest hardness area was at the interface between $\beta$-Ti layer and decarburized layer where the intermetallic compound phases were present, which, however, was strong enough to survive the water quenching operation. 

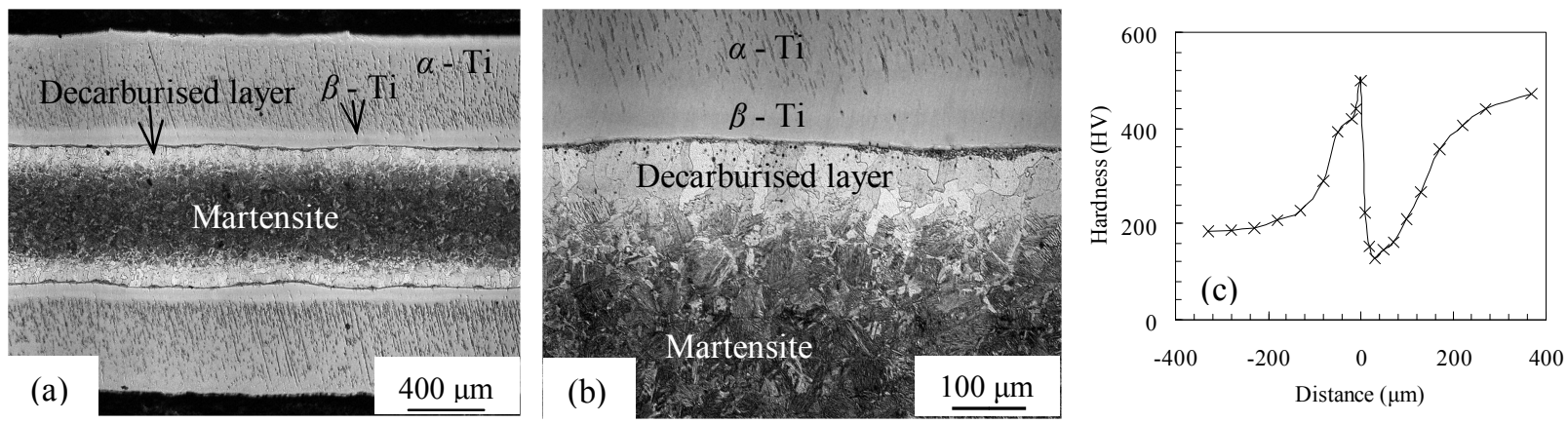

Fig. 5 Microstructure of hot-rolled Ti-clad carbon steel plate after water quenching from $900{ }^{\circ} \mathrm{C}$ : (a) cross sectional optical micrograph; (b) the same as (a) but with enlarged magnification; (c) Vickers hardness profiles measured across different phase layers.

\section{Summary}

It is feasible to produce Ti-clad carbon steel plates by a combination of diffusion-bonding and hotrolling process if the carbon content in the steel is not higher than $0.13 \mathrm{wt} \%$. During diffusion bonding process, the microstructure formed between $\mathrm{Ti}$ and carbon steel will consist of a $\beta$-Ti phase layer, a brittle phase layer of $\mathrm{TiC}$ and intermetallic compounds and a decarburised layer. During hot-rolling process, the brittle phase layer will not deform but fragment and the fragments will be distributed along the boundary between $\beta$-Ti phase layer and decarburised layer. From practical viewpoint, it is necessary to minimise the thickness of this brittle phase layer. This may be achieved by optimising the processing parameters of the diffusion bonding process such as diffusion temperature and time. Normal heat treatment procedures can be applied to the hot-rolled Ti clad carbon steel to adjust its mechanical properties, but the interfacial strength will be determined by the strength of intermetallic compound phases formed at the interface between $\beta$-Ti and decarburised layer.

\section{References}

[1] I. Rosenthal, A. Miriyev, E. Tuval, A. Stern, N. Frage, Characterization of Explosion-Bonded Ti-Alloy/Steel Plate with Ni Interlayer, Metallogr. Microstruct. Anal. 3 (2014) 97-103.

[2] J. Song, A. Kostka, M. Veehmayer, D. Raabe, Hierarchical microstructure of explosive joints: Example of titanium to steel cladding, Mater. Sci. Eng. A 528 (2011) 2641-2647.

[3] P. Manikandan, K. Hokamoto, A.A. Deribas, K. Raghukandan, R. Tomoshige, Explosive welding of titanium/stainless steel by controlling energetic conditions Mater. Trans. 47 (2006) 2049-2055.

[4] S.A.A. Akbari Mousavi, P.F. Sartangi, Effect of post-weld heat treatment on the interface microstructure of explosively welded titanium-stainless steel composite, Mater. Sci. Eng. A 494 (2008) 329-336.

[5] I. Tomashchuk, D.Grevey, P.Sallamand, Dissimilar laser welding of AISI316L stainless steel to Ti6-A14-6V alloy via pure vanadium interlayer, Mater. Sci. Eng. A 622 (2015) 37-45.

[6] T. Momono, T. Enjo, K. Ikeuchi, Effects of carbon content on the dif fusion bonding of iron and steel to titanium, ISIJ Int.. 30 (1990) 978-984.

[7] S. Kundu, S. Sam, B. Mishra, S. Chatterjee, Diffusion bonding of microduplex stainless steel and Ti alloy with and without Interlayer: Interface microstructure and strength properties, Mater. Metall. Trans. A 45 (2014) 371-383.

[8] S. Kundu, S. Chatterjee, Diffusion bonding between commercially pure titanium and micro-duplex stainless steel, Mater. Sci. Eng. A 480 (2008) 316-322.

[9] B. Qin, G.M. Sheng, J.W. Huang, B. Zhou, S.Y. Qiu, C. Li, Phase transformation diffusion bonding of titanium alloy with stainless steel, Mater. Charact. 56 (2006) 32-38. 